\title{
E Continua o Mundo Encantado das Cartilhas...
}

\author{
Mary Rangel \\ Universidade Federal Fluminense (UFF) \\ Universidade do Estado do Rio de Janeiro (UERJ)
}

Na perspectiva da Psicologia Social (no enfoque, moscoviciano, da representação), foram investigados conceitos e imagens do cotidiano popidar na cidade do Rio de Janeiro, conforme se apresentam em cartilhas adotadas em escolas públicas. Procurou-se, então, notar a possível influência da literatura citico-social da alfabetização (acentuada desde o final dos anos 70) que, entre outras questões, discute a dissociação entre conhecimento (escolar) e realidade, enfatizando o princípio de aprendizagens significativas e contextualizadas. Nas análises, confrontaram-se as representações com "indicadores sociais" do cotidiano, levantados em estudos sociológicos. Os resultados demonstraram a predominância de conceitos e imagens de situações que, não só se distanciam, como invertem as que se apresentam nos "indicadores ". Desse modo, permanece a constatação de que o mundo das crianças não encontra significado no mundo das cartilhas.

O mundo das cartilhas e o mundo real - sua aproximação ou distância nas representações - constituíram tema e motivação da pesquisa AIfabetização e representações do cotidiano na cidade do Rio de Janeiro, realizada na Universidade do Estado do Rio de Janeiro (Faculdade de Educação, curso de mestrado em Educação), em convênio com o Instituto Nacional de Estudos e Pesquisas Educacionais (INEP). O estudo iniciouse em 1991 e sua implementação concluiu-se em 1994.

A pesquisa orientou-se pela análise de representações do cotidiano das camadas populares (com atenção a conceitos e imagens de família, escola, trabalho, alimentação) em cartilhas de alfabetização adotadas em escolas públicas da cidade do Rio de Janeiro. 
Considerando-se as cartilhas ou outros textos de apoio à alfabetização como meios (significativos pela população e estágio de escolaridade que alcançam) de comunicação social, pode-se entender a importância de estudar a forma como "representam" a realidade cotidiana da camada majoritária da população brasileira em centros urbanos, como o Rio de Janeiro, de grande concentração popular.

O estudo de cartilhas atende, também, às observações de Soares (1989), no sentido de que "a produção sobre o tema cartilhas é, ainda, insuficiente" e de que "a cartilha no Brasil tem desempenhado papel fundamental no processo de alfabetização" (p.30).

Há que se notar, ainda, que os anos 80 e 90 distinguem-se, no Brasil, pela predominância de estudos críticos sobre alfabetização, consolidando uma nova percepção Crítico-Social, orientada por fundamentos progressistas; configura-se, deste modo, a alfabetização como processo vinculado à leitura de circunstâncias reais de vida.

A "visão crítica" da alfabetização "distintiva dos anos 80" (Soares, 1989, p.26) e o pensamento progressista que a orienta — no interesse do movimento, socioeducacional, de emancipação das camadas populares - incluem questionamentos às cartilhas, dirigidos, entre outros aspectos, às representações pouco realistas do cotidiano.

Justifica-se, assim, investigar se o pensamento Crítico-Social repercutiu na prática dos professores alfabetizadores, influindo na utilização de cartilhas ou outros textos (selecionados entre as publicações existentes ou produzidos pelos próprios professores ou alunos) que expressem o cotidiano das camadas populares a que se destinam.

É interessante, também, destacar na perspectiva atual da alfabetização, a substituição da ênfase em técnicas e em habilidades de prontidão, pela ênfase na construção (vocabulário, conhecimento, experiência, vivência) própria dos alunos.

A importância atribuída à construção própria dos alunos inclui sua percepção das circunstâncias que, realmente, os envolvem; nestas circunstâncias, manifestam-se os elementos (os fatos, os fenômenos e as palavras que os explicam) que fazem parte de sua vivência. Reforça-se, então, no processo de aquisição da linguagem, a sua vinculação à leitura das situações reais de vida. 
Embora a noção de "realidade" seja ampla e complexa, há, sem dúvida "indicadores" — baseados em estudos e observações consistentes, do ponto de vista teórico-prático - que apontam dados que elucidam, de maneira significativa, as condições reais da vida do cotidiano popular.

Desse modo, a pesquisa sobre Alfabetização e representações do cotidiano na cidade do Rio de Janeiro recorreu a informações do Instituto Brasileiro de Análises Sociais e Econômicas (IBASE), do I Censo da Criança e do Adolescente da Cidade do Rio de Janeiro (Prefeitura Municipal do Rio de Janeiro, novembro, 1990) e, Complementarmente, a observações feitas em escolas públicas, para reunir "indicadores sociais" desse cotidiano, com atenção às condições de vida, nos aspectos de família, escola, trabalho e alimentação.

O procedimento inicial foi, portanto, o levantamento de "indicadores sociais", a partir dos estudos sociológicos tomados como referência nesta pesquisa. Esse levantamento foi feito em relação a cada um dos elementos de análise - escola, família, trabalho, alimentação destacando-se os dados que demonstram a realidade cotidiana das camadas populares nos centros e periferias urbanas, com atenção à cidade do Rio de Janeiro.

Considerando que o estudo se aplicou à alfabetização de crianças, a questão do trabalho foi, então, analisada de forma associada à família, observando-se, também, indicadores sociais referentes a situações de subemprego do menor.

Em seguida, foi feito o levantamento de cartilhas adotadas em escolas públicas, localizadas em bairros populares (Zona Norte) da cidade do Rio de Janeiro. Assim, encontraram-se Belluci e Cavalcante, Kruel, Laurino e Musto, Moraes e Andrade (1985), Alves e Almeida (1990), Fonseca e Magalhães (1988), Marote (1991), Meireles e Meireles (1984), Mendes e Grillo (1991), Araújo (1989), Schinor (1990), Peixoto e Zattar (1990), Bragança, Carpaneda e Nassur (1990), Pires e Braga (1990), Passos e Silva (1990), Oliveira (1990), Correia e Galhardi (1992), Oliveira eBot(1990). 
Foi realizada, então, com base em Bardin (1979), a análise do conteúdo das cartilhas, observando-se, nas unidades de análise (palavras, frases, figuras), as representações de cada elemento do cotidiano, focalizado no estudo.

Além dos limites do alcance do estudo (o conjunto de cartilhas que constituíram o seu objeto) é importante, também, reconhecer os limites teóricos e metodológicos. Os limites teóricos referem-se, principalmente, à diversidade e abrangência de concepções da representação social e ao quadro conceitual que, como assinala Moscovici (1989), ainda está se construindo. Os limites metodológicos decorrem, fundamentalmente, das interpretações e "categorizações", próprias da análise de conteúdo.

Quanto à representação social, é necessário notar ^.polissemia e a diversidade de concepções.

Assim, na sociofilosofia marxista e em trabalhos nesta perspectiva, como os de Baczko (1985), Ansart (1978) e Chartier (1990), identificase representação com ideologia.

$\mathrm{Na}$ Psicologia Cognitiva, estuda-se a representação em suas implicações como processo mental de percepção e concepção dos fatos.

Já na Psicologia Social, cujo entendimento se tomou como referência nesta pesquisa, a representação (embora não se encontre uma definição, no sentido estrito do termo) é compreendida como conceitos e imagens que se formam no curso das interações e comunicações sociais, constituindo "categorias" explicativas dos fatos e comportamentos. No âmbito desta compreensão, admite-se que os fatos e comportamentos não só se "reflitam" nas representações, como possam ser constituídos, aceitos ou mantidos a partir delas, ou seja, do seu poder de influência no pensamento e nas ações sociais (Rangel, 1994b).

Segundo Spink (1993), a diversidade de noções da representação que a autora considera "desconcertante", remete, na Psicologia Social, ao debate epistemológico que se trava já nas origens das formulações teóricas do conceito.

$\mathrm{Na}$ gênese do debate, destacam-se dois fatos: o avanço a partir do conceito de representação coletiva, em Durkheim (1956), e o movimento da Psicologia, nos anos 60, na direção de pesquisas orientadas por interesses sociais, superando a tradição behaviorista. 
Assim, a discussão de representações - "sociais", nas origens e nos efeitos - foi incrementada na Psicologia Social em razão da insuficiência de modelos clássicos (particularmente o behaviorista) de explicação das interações dos sujeitos entre si e com o mundo. Essa discussão ocorre, portanto, no momento em que a Psicologia se mobiliza na direção de entender e intervir na realidade, deixando o plano abstrato de produção do conhecimento, para atuar em favor da solução de problemas sociais concretos. Um dos líderes desse movimento, que ocorre nos anos 60, na Europa, é Serge Moscovici.

A discussão das representações integra-se, portanto, a "novas e desejáveis orientações" para a Psicologia Social, podendo-se, por isso, falar no "advento da era das representações sociais" (Moscovici apud Vala, 1993, p. 16).

No enfoque da Psicologia Social, é relevante ainda assinalar a observação de Moscovici (1978), corroborado por autores como Ibánez (1988), quanto à complexidade dos "fenômenos sociais" de modo geral, e das representações, de modo particular, realçando-se a dificuldade em apontar uma definição, no sentido literal do termo.

... Las definicioncs nunca han constituido un proccdimiento muy interesante para dar cuenta de un concepto o de un fenômeno social, pero en este caso (de las representaciones) ni siquiera se nos ocurriría intentarlo. (Ibánez, 1988, p.32-33)

Ressalvando-se, então, os limites teóricos (afeitos, principalmente, à questão conceitual), pode-se compreender as contribuições desta perspectiva de investigação, no sentido de acrescentar, pela análise de representações, elementos de referência à compreensão do conteúdo do livro didático e cartilhas, ampliando ou complementando informações de estudos com o mesmo interesse temático, a exemplo dos de Ribeiro (1989), Faria (1985), Votre (1980).

A análise das representações, na ótica moscoviciana da Psicologia, enfatiza a atenção às percepções sociopsicocognitivas do real e aos conceitos e imagens que se constróem e se comunicam na "vida diária", considerando seus possíveis efeitos sobre a compreensão dos fatos e sobre as ações, orientadas por essa compreensão. 
Conceito e imagem - expressões da representação — são indissociáveis, ou seja, o conceito (idéia) incorpora a imagem (a figura), assim como a figura expressa, em si, o conceito. Na formação de imagens dá-se a concretização de conceitos. No dizer de Ibánez (1988, p.48), "Las imágenes ajudan a que las personas se forjen una visión menos abstrata del objeto representado...". Assim, as imagens encaminham "percepções" mais concretas do objeto.

Além de se constituir a partir de percepções da "realidade" (veiculadas pela interação e comunicação social), as representações também influem na constituição do "real", na medida em que essas percepções se consubstanciam em idéias, expressas em conceitos e imagens, que orientam valores e comportamentos.

É nesse sentido (de constituição do "real") que Ibánez (1988, p.37) assinala que "as representações sociais contribuem para constituir o objeto do qual são uma representação", e Vala (1993, p. 17 e 19) destaca a influência das representações na "organização significante do real" ou na "organização dos comportamentos e comunicações", "constituindo" papéis e configurando "realidades".

As representações constituem, então, o conhecimento prático, de senso comum, elaborado pelos grupos sociais e veiculado pela comunicação social, podendo influir nas visões, nos valores, nas condutas.

Compreende-se, desse modo, que, através de vários processos (psicológicos, cognitivos, culturais), as informações (as concepções) comunicadas socialmente podem ser assimiladas e consolidadas, influindo no pensamento e comportamento social, na compreensão do mundo e, também, nas percepções que os indivíduos têm de si próprios.

Conclui-se, portanto, que as representações do mundo nas cartilhas e livros didáticos, de modo geral, podem ter um significativo poder de influência sobre o leitor, sua visão dos fatos e de si mesmo.

Assim, a pesquisa sobre Alfabetização e representações do cotidiano na cidade do Rio de Janeiro orientou-se pelo entendimento da representação na perspectiva da Psicologia Social, procurando observar os conceitos e imagens do cotidiano, conforme se expressam nas cartilhas. 
O confronto do "mundo real" — considerando-se os "indicadores sociais" - e o "mundo das cartilhas" (observando-se as representações, com atenção a conceitos e imagens de familia, escola, trabalho e alimentação), oferece condições de se obter dados que interessam ao estudo da relação entre conhecimento (escolar) e realidade social.

É importante, então, retomar (e sublinhar) as críticas aos textos e imagens "irreais" que, pela força de influência dos livros, podem levar à visão distorcida dos fatos. Nesse sentido, lembram-se novamente os estudos de Faria (1985) sobre a ideologia do livro didático, de Ribeiro (1989) sobre o "fetiche do texto e a história" e de Nóbrega (1991) sobre a força das imagens que se apresentam nos livros.

E oportuno, também, rever trabalhos como o de Galzerani (1989), que (a partir de pesquisa, em que se reuniram e analisaram dados sobre livros didáticos) trazem questões que merecem especial consideração. Entre essas questões, encontra-se o reconhecimento do valor dos "estudos materialistas dialéticos", que entendem o livro como "elemento instituído, como produto e, ao mesmo tempo, como elemento que também institui, que cria a vida social" (p. 106). A par desse reconhecimento, observa-se o cuidado com a preservação do livro didático, relativizando-se as críticas:

$$
\begin{aligned}
& \text {... Se estivermos convictos do caráter contraditório da linguagem escrita, } \\
& \text { mesmo que voltada para a reprodução dos valores socialmente dominantes, } \\
& \text { se estivermos abertos para a valorização da capacidade de percepção analítica } \\
& \text { dos alunos, poderemos repensar a forma de atuação em sala de aula, com } \\
& \text { estes mesmos livros didáticos... (Galzerani, 1989, p. 108-109) }
\end{aligned}
$$

Entretanto, embora se considere a importância da forma de trabalho com os livros, não se pode negar o poder de influência do conteúdo do texto sobre o leitor. Essa influência (sobre o pensamento e a aceitação dos fatos e situações "representados" nos livros) encontra respaldo em Moscovici (1978; 1981; 1989), quando discute a formação do conhecimento social pelos conceitos e imagens veiculados nas representações. Também em Bazcko (1985), Ansart (1978) e Chartier (1990), na ótica marxista de entendimento das representações, encontram- 
se argumentos em favor do exame crítico dos conceitos e imagens que podem influir em percepções distorcidas e alienadas da realidade.

Sublinha-se, portanto, a relevância do confronto dos dados do cotidiano (conforme se apresentam nos "indicadores sociais") e as representações das cartilhas, no interesse de uma leitura contextualizada.

Os "indicadores sociais" levantados neste estudo mostram dados que, embora se tenha o cuidado de não generalizar para toda a realidade do cotidiano popular na cidade do Rio de Janeiro, apontam para alguns aspectos que podem ser levados em consideração, como os que se exemplificam em seguida.

Nas escolas (Zona Norte, periferia) observadas, verificou-se, quanto à familia, que nem sempre os alunos residiam com os pais ou, mesmo, tinham pai e mãe; com freqüência, moravam com avós, tias ou irmãos mais velhos. Quanto à escola, permaneciam situações de dificuldades, a exemplo da manutenção e conservação de prédios e instalações, material escolar, uniforme, locomoção dos alunos, evasão e repetência. Quanto ao trabalho, destacavam-se os problemas de desemprego, subemprego e instabilidade. Nem sempre os responsáveis estavam trabalhando, encontrando-se, com freqüência, pais que apenas faziam serviços esporádicos, como vigias ou auxiliares de obras, e mães que também trabalhavam, por períodos curtos e incertos, como empregadas domésticas. O subemprego também alcança as crianças, que assumem trabalhos de guardadores de carro ou vendedores (de produtos diversos) nas ruas. Quanto à alimentação, observou-se, principalmente, a escassez e a qualidade deficiente, reduzida a farináceos.

Esses aspectos (com que se exemplificam alguns "indicadores sociais") aproximam-se da realidade de pobreza, denunciada no estudo de Votre, quando fala da criança da camada popular que usa cartilhas:

... é uma criança fraca, não bem nutrida, que mora mal e veste pior; sua casa ou barraco ou apartamento não se localizam em lugares bem urbanizados (ou sequer urbanizados); nos barracos não há água encanada nem esgoto (Votre, 1980, p.21). 
Os "indicadores" da realidade social, quando comparados às representações de cartilhas, permitem notar que, apesar da literatura Crítico-Social enfatizada desde o final dos anos 70, ainda se encontram, nos anos 90, textos (predominantes, no conjunto dos que foram examinados) que veiculam conceitos e imagens distantes da vida real da população que as utiliza.

Observando-se, mais diretamente, cada um dos aspectos examinados nas representações - escola, família, trabalho, alimentação - , confirma-se a predominância de situações alheias às que se confrontam no dia-a-dia da maioria da população. Retomando alguns exemplos dessas situações (Rangel, 1994a), pode-se demonstrar este alheamento.

Nas representações de escola, encontram-se, então, as bonitas pastas, uniformes e materiais escolares diversos, incluindo cartazes, lápis de cor, "giz de cera". Por isso, "Para Laila, ir para a escola é uma festa" (Bragança, Carpaneda, Nassur, 1990, p.123).

E é também na "escola ideal" que o aluno "capaz" só "tira nota dez" e faz a professora "feliz": "... Diniz, então, falou: — Vou tirar nota dez. Sou um menino capaz! Dona Zilá ficou muito feliz com seu aluno Diniz". E, se o "menino capaz" só "tira nota dez", o que "tira zero" "nada é": "...Seu nome era zero. Ele só andava vazio. De nada era" (Marote, 1992, p.85). Assim, por conta da aprendizagem do "z", a nota dez se estabelece como medida de valor, na escola e na vida.

É interessante, ainda, perceber que o "menino capaz" não é aquele que vai de ônibus à escola, pois ele se locomove de "táxi": "... Hoje tomei um táxi. O motorista chama-se Max. O táxi dele não tem ponto fixo. $\mathrm{Eu}$ gritei táxi e ele parou" (Marote, 1992, p.102). Observa-se, portanto, que a leitura correta do " $\mathrm{x}$ " interfere na leitura correta da vida.

Da mesma forma que a escola, a predominância das representações de trabalho mostra a situação de posse de bens materiais inacessíveis à quase totalidade da população. É o que acontece, por exemplo, com o avô do personagem da cartilha de Alves e Almeida (1990, p.61), cuja situação de trabalho e bens é ilustrada pela imagem do "casarão" da fazenda (com dez janelas), cercado de plantas e gado 
Também em Fonseca e Magalhães (1988, p.99), a situação (ideal) de trabalho permite à família, "contente", fazer compras em "ótimos supermercados".

Pode-se, então, observar que as representações predominantes de família mostram um cenário de facilidades e sucesso. É curioso notar, neste cenário "ideal", a figura da "noiva", em sua "festa de noivado": "... Margarida ficou noiva de Carlos. Ela ganhou um belo anel de ouro. Carlos estava de terno novo na festa. Margarida ficou muito bonita com o vestido verde e botas de verniz" (Oliveira, 1990, p.65). E assim, a leitura do "v" ganha sentido no contexto da frase, mas perde sentido no contexto da vida.

A boa condição de trabalho e a boa condição de família permitem, também, ao "papai" possuir um "fusca maluco": "...O fusca de papai é maluco. Não pode ver uma brasília..." (Pires e Braga, 1990, p.86). Aprende-se, portanto, a diferença do som do "s" através da diferença da realidade das pessoas que (aglomeradas nas conduções coletivas) sequer podem sonhar com a posse de "fuscas" ou "brasílias".

Pode-se, então, reafirmar que as situações "idealizadas" de família e trabalho não expressam a realidade do cotidiano popular, em que, observando-se os "indicadores sociais", o desemprego e o subemprego afetam a condição de sobrevivência da família, que não tem "fusca", não tem "belo anel de ouro" e, muito menos, "botas de verniz". A situação real apresenta-se, excepcionalmente, em Correia e Galhardi (1992,p.77):

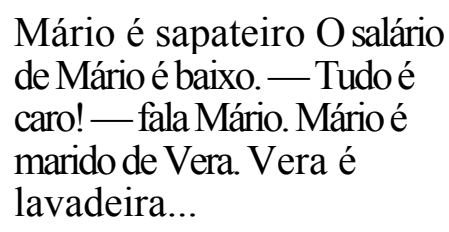

A situação de família e trabalho "representada" em Correia e Galhardi (1992) distingue-se em meio a conceitos e imagens de conforto e riqueza, que prevalecem nos textos das cartilhas analisadas. 
E, da mesma forma, ideal, configuram-se as representações de alimentação, exceto, também, em Correia e Galhardi, quando se aproximam do real, na questão da fome (problema cuja dimensão mobiliza, hoje, uma campanha nacional) e da solidariedade, enquanto valor que flui no enfrentamento dos desafios diários das comunidades:

Messias tem dezesseis anos e mora numa favela.

Messias passa fome (...)

Certo dia, choveu sem parar.

O barraco de Messias foi levado peia enxurrada.

A mãe de Messias ficou assustada e disse:

- Nossa! O que vamos fazer?

Os amigos ajudaram a família de Messias

a levantar um barraco! (Correia, Galhardi, 1992, p.107).

Entretanto, na predominância dos textos, encontram-se abstrações dos fatos, a exemplo dos conceitos e imagens de fartura e variedade de alimentos. Assim, entre os produtos que "mamãe" compra "a quilo" encontram-se o "presunto, o frango, as frutas, o café, a salsicha" e, entre os que ela compra "a litro" ou em garrafa, os "sucos, o vinho, o leite" (Passos e Silva, 1993, p. 121).

$\mathrm{Na}$ mesma condição, "abstrata", encontra-se a personagem de Mendes e Grillo (1991), numa lanchonete, consumindo "sanduíche, suco e sorvete" (p.22 e 48). Reforçando a condição de riqueza, em outras situações a personagem encontra-se dirigindo uma "lancha a motor" (p.42), ou rodeada de presentes e "rosas", numa "linda" festa de aniversário (p.2627).

A alimentação farta e variada também se "representa" em Peixoto eZattar(1990, p.67), quando hortaliças, ovos, presunto, queijo, manteiga, chocolate e iogurte são preparados por "mamãe".

Representações como essas demonstram que a alimentação, nas cartilhas, contradiz e nega a escassez de quantidade e qualidade de alimentos consumidos no cotidiano popular.

Confrontados com os "indicadores sociais", os conceitos e imagens "ideais" expressam situações de família, escola, trabalho, e alimentação

R. bras. Est. pedag., Brasília, v.74, n.178, p.639-654, set./dez. 1993 
que não são vividas ou reconhecidas pelas crianças das camadas populares, que são os leitores (majoritários) das cartilhas na cidade do Rio de Janeiro. O mundo dessas crianças, portanto, não encontra significado no mundo das cartilhas.

Pelos exemplos apontados (e nos limites do alcance deste estudol pode-se perceber que, predominantemente, as representações que se encontram nos textos das cartilhas (os conceitos e imagens que nelas se expressam) não só se distanciam como invertem as situações reais. E isto acontece, decorrida mais de uma década em que a literatura Crítico-Social destaca e fundamenta o princípio das aprendizagens significativas, do ponto de vista pedagógico e social.

Observando-se o interesse em não radicalizar a crítica epreservar a valorização do livro didático (e, portanto, da cartilha e da iniciativa de seus autores), as análises deste estudo se propõem menos a denúncias $e$ mais a considerações que salientem a importância da leitura crítica e a influência da representação dos fatos nas percepções que orientam essa leitura. Essas considerações confirmam a necessidade da atenção ao conteúdo dos livros que se vinculam ao ato (pedagógico e social) de ensinar e aprender.

Assinala-se ainda que, observando-se representações de fatos mais reais, já encontrados em publicações como a de Correia e Galhardi (1992), é possível acreditar que, com a continuidade deste tipo de pesquisa (ampliando-se o alcance do estudo) possam se encontrar cartilhas ou textos resultantes de produções nas escolas, que encaminhem a leitura - real - do cotidiano.

Conclui-se, então, a pesquisa com a esperança de que a beleza do mundo encantado das cartilhas possa ser superada pela beleza de um mundo real, mais justo e menos desigual: um mundo bonito de se ler e se viver.

\section{Referências bibliográficas}

ALVES, E., ALMEIDA, M. da. Davi, meu amiguinho. Rio de Janeiro: Bloch, 1990. 
ANSART, P. Ideologia, conflitos e poder. Rio de Janeiro: Zahar, 1978.

ARAÚJO, S.M. Caderno cartilha — alfabetização. Atividades. São Paulo: Ed. do Brasil, 1989.

BACZKO, B. Imaginação social e utopia. In: ENCICLOPÉDIA Einaudi; anthroposhomem. [s.1]: Imprensa Oficial/Casa da Moeda, 1985. v,5, p.296-386.

BARDIN, L. Análise de conteúdo. Lisboa: Telles da Silva, 1979.

BRAGANÇA, AO CARPANEDA, IP. de, NASSUR, RIM. Porta de papel. São Paulo: FTD, 1990.

CHARTIER, R. História cultural. Rio de Janeiro: Bertrand Brasil, 1990.

CORREIA, ME., GALHARDI, M. Cartilha como é fácil. São Paulo: Scipione, 1992.

DURKHEIM, E. Les règles de là méthode sociologique. Paris: PUF, 1956.

FARIA, AL.O. de. Ideologia no livro didático. São Paulo: Cortez, 1985. (Coleção polêmicas do nosso tempo).

FONSECA, T.N. da, MAGALHÃES, J.M. Pompom, meu gatinho. Rio de Janeiro: Livro Técnico, 1988.

GALZERANI M.C. Belas mentiras: a ideologia nos estudos sobre o livro didático. In: PINSKY, J. (Org.) O ensino da historia e a criação do fato. São Paulo: Contexto, 1989

IBÁNEZ, GT. Representaciones Sociales: teoria y metódo: In: IDEOLOGIA de là vida cotidiana. Barcelona: Sendai, 1988. p. 15-89.

MAROTE, D'01im. Cartilha aquarela. São Paulo: Ática, 1992.

MARTINS, M.H. FELÍCIO, R. Construindo o conhecimento: Estudos Sociais e Ciências. 1 série. São Paulo: FTD, 1990.

MEIRELES, J. MEIRELES, E. A casinha feliz. Rio de Janeiro: Record, 1984.

MENDES, SR., GRILLO, L. S. Cartilha da Angélica. Rio de Janeiro: Bloch, 1991.

MORAES, L .M.de, ANDRADE, M. Mundo mágico: Comunicação e Expressão. SãoPaulo: Ática, 1985.

MOSCOVICI, S. A representação social da psicanálise. Rio de Janeiro: Zahar,

On social representations. In: J.P Forgas (ed). Social cognition: Perspectives on everyday understanding. London: Academic Press, 1981.

R. bras. Est. pedag., Brasília, v.74, n.178, p.639-654, set./dez. 1993 
Des représentations collectives aux représentations Sociales. In: JODELĖT, D. Les représentations Sociales. France: Press Universitaires 1989. p.62-86.

NÓBREGA, F. A função da imagem do livro, a direção do olhar. Releitura Belo Horizonte, n.10, p.28-31, ago/set. 1991.

OLIVEIRA, M. do CM. de. Leiturinhas. Rio de Janeiro: Livro Técnico, 1990.

OLIVEIRA, P.S. de, BOT, A.C. No reino da natureza. São Paulo: Ática, 1990.

PASSOS, C, SILVA, Z. Eu gosto de Estudos Sociais. São Paulo: Nacional, 1993.

PEIXOTO, M.L., ZATTAR, SM. Bom tempo. São Paulo: Moderna, 1990.

PÍRES, A., BRAGA, T. No jardim do faz-de-conta. Rio de Janeiro: Livro Técnico,

RANGEL, M. Representação e leitura crítica do mundo nos livros didáticos. Niterói: UFF, 1994a. mimeo. Vozes, $1994 \mathrm{~b}$.

RIBEIRO, L.F O fetiche do texto e a história. Niterói: UFF, 1989. mimeo.

SCHINOR V.R.R. Eu vou construindo, alfabetizando. São Paulo: Ed. do Brasil, 1990

SOARES, M. Alfabetização no Brasil: o estado do conhecimento. Brasília: REDUC: INEP, 1989.

SPINK, M.J. (Org). O conhecimento no cotidiano: as representações sociais na perspectiva da Psicologia Social. São Paulo: Brasiliense, 1993. p.85108: O estudo empírico das representações sociais.

VALA, J. Representações sociais: para uma psicologia social do pensamento social. in: VALA, J., MONTEIRO, MB. Psicologia Social. Lisboa: Fundação Calouste Gulbenkian, 1993. p. 1-14.

VOTRE. S.J. Por uma lingüística aplicada à alfabetização. Porto Alegre, n.42, p.20-34, dez. 1980.

Recebido em 25 de outubro de 1994

Mary Rangel, doutora em Educação, pela Universidade Federal do Rio de Janeiro (UFRJ), é professora das Faculdades de Educação da 
Universidade Federal Fluminense (UFF) e da Universidade do Estado do Rio de Janeiro (UERJ).

In the perspective of Social Psychology (in the Moscovite focal point of the representation), concepts and images of the popular quotidian in Rio de Janeiro city have been investigated, as they present themselves in the spelling books adopted in public schools. One endeavoured, then, to note the possible influence of the critical-social literature of the first year of schooling (accentuated since the end of the 70s), which, among other matters, discusses the dissociation between knowledge (scholar) and reality, enphasizing the principle of significative and contextualized apprendticeships. In the analysis, the representations confront themselves with "social indicators" of the quotidian, raised up in sociologie studies. The results demonstrated the predominance of concepts and images of situations which not only keep away from, as well as invert the ones which present themselves in the "indicators ". Thus, endures the evidence that the world of the children does not find significance in the world of the spelling books.

Sous la perspective de la Psychologie Sociale, d 'après Moscovici (1978), ont été analises concepts et images du quotidien populaire dans la ville de Rio de Janeiro, selon ils se présentent dans les abécédaires adoptés dans les écoles publiques. Nous avons cherché, alors, observer la possible influence de la littérature critique-sociale (accentuée dès le final des années 70) sur l'alphabétisation. Cette littérature, parmi d 'autres questions, discute la dissociation entre savoir (scolaire) et réalité, en emphatisant le principe des apprentissages significatifs et contextualisés. Dans les analyses se confrontent les représentations avec les "indicateurs " sociaux du quotidien, relevés dans les études sociologiques. Les résultats ont démontré la prédominance des concepts et des images de situations que, non seulement s'éloignent comme inversent celles qui se présentent dans les "indicateurs". Ainsi, il nous reste la constatation que le monde des enfants ne recontre pas de signification dans le motide des abécédaires. 
En la perspectiva de la Psicoligia Social (en el enfoque moscoviciano de la representación), se investigaron conceptos y imágenes de lo cotidiano popular en la ciudad de Rio de Janeiro, según se presentan en cartillas adoptadas en escuelas públicas. Se procuró observar la posible influencia de la literatura crítico-social de la alfabetización, incrementada desde finales de los años setenta, que, entre otros temas, discute la disociación entre conocimiento (escolar) y realidad, enfatizando el principio de aprendizajes significativos y contextuados. En los análisis se confrontali las representaciones con "indicadores sociales" de lo cotidiano, obtenidos en estudios sociológicos. Los resultados han demostrado la predominancia de conceptos e imágenes de situaciones que no sólo se alejan, sino que invierten las presentadas en los "indicadores ". De esta manera, permanece la constatación de que el mundo de los niños no encuentra sifnificado en el mundo de las cartillas. 